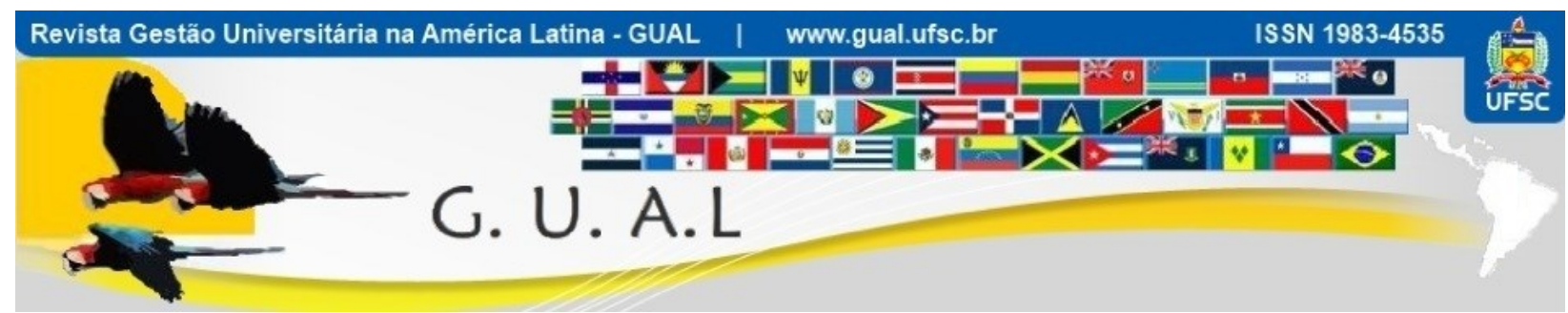

DOI: http://dx.doi.org/10.5007/1983-4535.2017v10n3p228

\title{
A MICROFILMAGEM DE DOCUMENTOS DA UNIVERSIDADE FEDERAL DE SANTA CATARINA: UMA ANÁLISE SOBRE PRÁTICAS E NORMATIVAS ARQUIVÍSTICAS
}

\section{INTEREST AND ATTITUDE OF THE BOARD OF ACCOUNTING STUDENTS AND SCIENCE IN RELATION TO BASIC TRAINING COURSES}

Nei Antonio Nunes, Doutor

Universidade do Sul de Santa Satarina - UNISUL neinunes@bol.com.br

Sílvia Cintra Borges, Mestre Universidade do Sul de Santa Satarina - UNISUL silviacb83@hotmail.com

Jacir Leonir Casagrande, Doutor Universidade do Sul de Santa Satarina - UNISUL jacir.unisul@gmail.com

André Luis da Silva Leite, Doutor Universidade Federal de Santa Catarina - UFSC andre.leite@live.com

Recebido em 24/agosto/2015

Aprovado em 14/julho/2017

Sistema de Avaliação: Double Blind Review

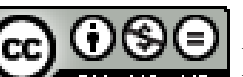

Esta obra está sob uma Licença Creative Commons Atribuição-Uso. 


\title{
RESUMO
}

Este estudo visa analisar o processo de microfilmagem de documentos e sua aplicabilidade no Setor de Microfilmagem da Universidade Federal de Santa Catarina. Para tanto, se propõe a identificar as diferenças e semelhanças existentes entre a teoria e as práticas exigidas no processo de microfilmagem. Esta pesquisa teve abordagem qualitativa e o procedimento investigativo utilizado é o "estudo de caso". Com ele, procura-se elucidar o intrincado mosaico existente em situações cotidianas complexas e, nesse intento, utiliza-se, como passos metodológicos constitutivos da pesquisa, levantamento de dados por meio de entrevista semiestrutura e observação participante. Nesta pesquisa foram apresentados os procedimentos adotados durante o processo de microfilmagem, desde a seleção dos documentos a serem microfilmados até o armazenamento, destacando-se também a comparação entre o sistema híbrido e a microfilmagem expondo a legalidade dos dois sistemas, suas vantagens e desvantagens. Conclui-se, contudo, que é mister a implantação de um Sistema de Arquivos como condição de viabilidade para o gerenciamento total dos arquivos em todos os seus suportes.

Palavras chave: Microfilmagem. Preservação. Informação. Acesso.

\begin{abstract}
This paper aims to analyze the process of documents microfilming and its applicability in the Federal University of Santa Catarina. We aimed to identify the differences and similarities between theory and practice required during the microfilming process. This is a qualitative research, as we use a case study as the main method of investigation, which focuses on elucidating the occasional actions in complex everyday situations for treatment through experiments or data collection. Through a questionnaire we found the need for a Disposal Agreement and also a File System. We also presented the procedures adopted during the microfilming process, from the selection of documents to be microfilmed to storage, also standing out the comparison between the hybrid system and microfilming exposing the legality of the two systems, their advantages and disadvantages. However, we concluded that only with the implementation of a file system the management of all files will be possible.
\end{abstract}

Keywords: Microfilm. Preservation. Information. Access. 


\section{INTRODUÇÃO}

A partir do momento em que o homem começou a utilizar à escrita como meio de comunicação e conservação de registros destinados a transmitir seus conhecimentos às gerações futuras, surgiu como consequência inevitável o problema do armazenamento inadequado da informação. Por isso, no século XIX, época marcada por grandes avanços técnicos e científicos, surgiu o microfilme, que se configurou por meio da conjugação do processo fotográfico, em desenvolvimento na época, ao registro de documentação escrita, conforme relata Souza Neto (1979).

Segundo Bellotto (1991, p. 282), “a documentação conservada nos arquivos, antes de ser um bem nacional, faz parte do Patrimônio cultural comum da humanidade", por isso devese preservar, a fim de conservar os documentos que integram um arquivo para evitar perdas da memória das pessoas ou instituições.

Todavia, um dos aspectos mais sensíveis, derivado da avalanche de registros, resultado da incrível expansão cultural e científica dos últimos séculos, é o problema das grandes áreas ocupadas por arquivos convencionais de documentos em suporte papel. Por isso, a microfilmagem representa uma forma segura, limpa e moderna de se manusear informações de um documento de arquivo, qualquer que seja o objetivo básico do sistema em uso. Inúmeras são as vantagens inerentes à microfilmagem de documentos, já que ela não representa apenas uma forma de manutenção de arquivo permanente. Tornou-se, isto sim, uma ferramenta moderna, capaz de dinamizar o manuseio de informações, sempre pronta a fornecer, com rapidez e segurança, as mais eficazes soluções.

Nos últimos anos, os filmes tornaram-se um importante material documentário, e seu uso para essa finalidade vem aumentando rapidamente. A quantidade crescente e o valor dos microfilmes usados pelas instituições financeiras, bibliotecas, órgãos do governo e empresas exigem cuidados com tais registros, para assegurar sua máxima duração.

A permanência dos registros fotográficos depende da estabilidade química do filme, de como ele é processado e das condições nas quais são armazenados depois de prontos. A estabilidade das camadas do filme é determinada na fabricação, no processamento, porém sob o armazenamento o controle já não recebe a devida atenção na maioria das instituições que o utilizam no Brasil.

Na Universidade Federal de Santa Catarina (UFSC), localizada na cidade de Florianópolis, em Santa Catariana, assim como na maioria das instituições de ensino superior 
(IES), é nítida a necessidade de um tratamento adequado dos seus arquivos, para a administração e funcionamento dos mesmos. Por isso, cada vez mais, os dirigentes das instituições de ensino buscam avanços nos serviços de arquivos. No caso da UFSC, existe também a preocupação com a preservação com o intuito de possibilitar, além do acesso atual, a perpetuação dos documentos da universidade.

Deste modo, com o crescimento do volume documental, no ano de 1981 foi implantado o Setor de Microfilmagem/UFSC para auxiliar no processo de gestão da informação, visando a preservação dos documentos, a otimização de espaço físico e o acesso seguro e eficiente à informação.

A relevância do estudo ora apresentado se dá, sobretudo, pela importância e urgência da preservação de documentos - muito deles permanentes - que contam, por exemplo, a história da Universidade Federal de Santa Catarina. Em face da validade científica e social do processo de microfilmagem, mas também dá necessidade de que seus procedimentos se conformem cada vez mais aos preceitos legais, a pesquisa busca responder ao seguinte problema: Os procedimentos adotados e, consequentemente, sua aplicabilidade durante o processo de microfilmagem de documentos no Setor de Microfilmagem da UFSC estão em conformidade com a legislação vigente?

Um arquivo microfilmado constitui-se em uma fonte de informações imediatas e de consulta fácil, por isso para muitas instituições a microfilmagem é de grande utilidade. A armazenagem dos documentos microfilmados economiza espaço físico, reduz o número de gabinetes de arquivo em uso ativo e diminui o espaço que se utilizará eventualmente para a armazenagem de material inativo. Para Andrade (2006), a microfilmagem de documentos e registros pode reduzir até $98 \%$ o espaço exigido para arquivar.

As máquinas e equipamentos utilizados para a microfilmagem têm que ser apropriadas, dependendo do tipo de documento, assim como os processos de execução das rotinas da microfilmagem. Estes têm o seu início com a solicitação do documento a ser microfilmado. O processo desenvolve-se até a entrega do microfilme ao solicitante - todas as suas etapas devem ser rigorosamente observadas.

O planejamento e a política de microfilmagem também devem ser considerados. Para tanto, é mister que com os funcionários sejam bem treinados, pois isto permite que todas as etapas sejam operacionalizadas, de tal forma que se origine o microfilme conforme previsto e 
de acordo com as normas legais. Por isso, cabe aos profissionais da área estar atentos às transformações tecnológicas que podem impactar no processo de microfilmagem.

Além disso, é necessário seguir determinadas prescrições de segurança como: guardar cópias de documentos em espaço seguro, distante do lugar onde se conservam os originais, facilmente é possível fazer duplicatas de rolos de filmes ou de grupos de cartões perfurados para filmes. Conforme Luther (1979), a armazenagem em locais diferenciados protege em caso de incêndio ou de qualquer outro sinistro. As cópias também podem ser distribuídas a outros locais para seu uso ou referência.

Percebe-se, assim, a necessidade de conhecer a técnica e procedimentos, como também a legislação vigente sobre a microfilmagem, levando sempre em consideração o planejamento das atividades durante todo o processo. Por isso, a intenção deste trabalho é identificar os procedimentos adotados no processo de microfilmagem de documentos, sua aplicabilidade na Universidade Federal de Santa Catarina, e sua adequação ao ordenamento jurídico.

Em face do exposto, e ratificando o que foi indicado anteriormente, a justificativa da pesquisa está, justamente, na relevância científica e social de se buscar identificar onde a universidade se baseia para construir uma política de organização e preservação, verificando a legislação e o tratamento adequado, tanto no conteúdo teórico da Arquivologia quanto na sua manutenção permanente, tendo como documento o microfilme.

\section{GESTÃO DOCUMENTAL E MICROFILMAGEM}

O Setor de Microfilmagem é compreendido como uma unidade de tratamento documental e gerencial que possui o controle de todos os documentos que serão microfilmados e eliminados.

A Gestão de Documentos "compreende na responsabilidade dos órgãos produtores e das instituições arquivísticas em assegurar que a documentação produzida seja o registro fiel das suas atividades e que os documentos permanentes sejam recolhidos às instituições" (Bellotto, 1991, p.46)

Segundo a Lei 8.159 de 8 de janeiro de 2001 a gestão de documentos é “o conjunto de procedimentos e operações técnicas à sua produção, tramitação, uso, avaliação e arquivamento em fase corrente e intermediária, visando a sua eliminação ou recolhimento para guarda permanente". Para um gerenciamento de documentos eficaz pode-se destacar 
duas ferramentas básicas e indispensáveis: o Plano de Classificação de Documentos e a Tabela de Temporalidade e Destinação de Documentos. Estas ferramentas permitem simplificar e racionalizar a gestão dos documentos de forma a recuperar a informação arquivística com agilidade e precisão. Permitem, ainda, eliminar os documentos destituídos de valor permanente, preservando os detentores de tal valor.

Para Paes (2004), a gestão Arquivística de Documentos é uma ferramenta indispensável para dar suporte aos documentos, considera-se, em primeiro lugar, que os documentos arquivísticos conferem às entidades a capacidade de:

- conduzir as atividades de forma transparente, possibilitando a governança e o controle social das informações;

- apoiar e documentar a elaboração de políticas e o processo de tomada de decisão;

- possibilitar a continuidade das atividades em caso de sinistros;

- proteger os interesses do órgão ou entidade e os direitos dos funcionários e dos usuários ou clientes;

- assegurar e documentar as atividades de pesquisa, desenvolvimento e inovação, bem como a pesquisa histórica;

- manter a memória corporativa e coletiva.

Enfim, tudo isto somente será possível se for implantado um programa de gestão arquivística de documentos, aplicável a ambientes convencionais, digitais ou híbridos.

A conservação dos acervos de documentos em suporte de papel tem preocupado as instituições arquivísticas, em especial, pela deterioração desse patrimônio e a precariedade em que se encontram esses acervos. Isso o que se leva a enfatizar a importância de adotar uma política de preservação como a microfilmagem de documentos.

A necessidade da preservação de documentos é um dos mais sérios problemas com que se depara o arquivista. Sabe-se que o espaço exigido para a sua conservação é muito grande, por vezes incompatível com a estrutura física/espacial, já que a massa documental a ser preservada cresce extraordinariamente nas instituições, sejam elas públicas ou privadas. A microfilmagem é uma alternativa na resolução deste e de outros problemas. Como explica Antunes:

A microfilmagem é uma técnica de miniaturização, sobre filme, de qualquer documento existente num suporte de papel e em meio eletrônico, com o objetivo de preservar o seu conteúdo intelectual para o futuro. Essa técnica vem sendo aplicada há várias décadas, com o desenvolvimento de novos métodos que permitem melhorar este processo. O sistema micrográfico 
encontra-se perfeitamente regulamentado, e está alicerçado num conjunto de normas internacionais que dão garantia de qualidade. $\mathrm{O}$ microfilme sendo produzido e mantido em condições adequadas garante uma longa vida às informações (ANTUNES, 2009, p. 15).

Em 1871 inicia a aplicação do microfilme à reprodução de registros comerciais em larga escala. Segundo Luther (1979, p. 109), este movimento pode ser considerado como a "primeira aplicação do microfilme na preservação de registros comerciais". Assim, foi com os inventores do século XIX que o mundo conheceu, experimentou, aprovou e adotou o uso do microfilme.

Os sistemas de microfilme basearam-se, principalmente, nos processos fotográficos e se desenvolveram como uma consequência natural das aplicações técnicas da fotografia. No início, a microfilmagem era uma aplicação pura da técnica fotográfica. Com o passar do tempo, contudo, o conhecimento de seus princípios e fundamentos tornou-se essencial para uma boa compreensão da microfilmagem como sistema.

Microfilmagem, segundo Andrade (2006), é uma cópia idêntica do documento original, reformatada para um novo suporte, cuja base é constituída de plástico transparente e flexível. Pode-se inferir, então, que a microfilmagem é um sistema de reprodução de documentos que utiliza a miniaturização da imagem como agente principal, ou seja, podem ser admitidas distintas formas de arquivos, levando-se em conta os recursos financeiros disponíveis e até mesmo o bom senso dos administradores. Aliás, é importante destacar que as formas de arquivamento, combinadas com o emprego de tecnologia, podem ser definidas de acordo com o valor financeiro disponível e prioridades administrativas da instituição.

O sistema de microfilmagem realiza mecanização em equipamentos, os quais, segundo a classificação acima, irão se constituir nas unidades básicas do sistema.

As microfilmadoras permitem o registro das informações no microfilme, chamado de "unidades de entrada" do sistema, apresentando recursos variados, de acordo com cada modelo. Elas podem gravar diretamente do documento, à medida que o operador faça o mesmo passar pelo campo fotográfico da máquina, ou então, gravar diretamente a partir dos impulsos de uma fita magnética, do tipo usado em processamento eletrônico de dados. As processadoras de microfilmes possuem, em sua maioria, alto grau de automação oferecendo aos usuários comodidade e segurança no manuseio de microfilmes.

Os equipamentos que possibilitam a leitura das informações contidas no microfilme são chamados de leitores, também denominados de unidades de saída. Estas unidades 
assumem diversos modelos para atender necessidades específicas ou apresentar múltiplo uso, como ter apenas um visor de microfilmes, ou um visor-copiador, capaz de gerar uma cópia em papel, de um documento qualquer microfilmado, em apenas alguns segundos.

A microfilmagem é o único processo de reprodução de documentos que possui respaldo arquivístico legal, garantindo a permanência das informações registradas e permitindo o acesso em leitoras e, principalmente, preservando os originais.

Cabe ilustra, as instituições que detêm em sua guarda documentos da terceira idade, os de guarda permanente, obras raras e coleções de periódicos que são consultados com certa frequência ou apresentam problemas de conservação, utilizam esse sistema. Dentre elas: Arquivos Públicos, Bibliotecas, Museus, Centros de Documentação e Memória.

O CONARQ (Conselho Nacional de Arquivos) orienta que antes do descarte dos documentos é preciso realizar um estudo meticuloso das leis federais, estaduais e municipais que norteiam essa atividade. Deve ser elaborado um certificado que informe que o filme é uma cópia verdadeira e fiel do documento original e, quando o filme deverá ser destruído, arquivando o certificado de destruição.

Enfim, a microfilmagem favorece o sigilo das informações, permite a redução de espaço e peso, em 90\%, o uso regulamentado por leis específicas, além de dificultar a falsificação.

O sistema híbrido é a junção de mais de uma tecnologia, aproveitando o melhor que cada uma tem a oferecer, com o objetivo de potencializar resultados, como: microfilmagem e digitalização. Enquanto a primeira é realizada para a preservação do documento original e da informação nele contida, conforme afirma Andrade (2007), a digitalização é utilizada para agilizar a recuperação e a disponibilização da informação.

A implantação de sistemas híbridos de documentos de arquivo tem sido descomplicada pelo uso de equipamentos como computadores, leitores e scanners de microformas. Basicamente existem duas formas de adoção do sistema híbrido: utilizando equipamentos separados (microfilmadora e scanner de microformas) e utilizando equipamento híbrido (digitalização e microfilmagem realizadas pelo mesmo equipamento). Cabe dizer, finalmente, que para a preservação o sistema híbrido "ideal" - mais eficiente - é aquele que utiliza o microfilme como plataforma para o meio digital. 


\section{METODOLOGIA}

O ambiente da pesquisa é a Universidade Federal de Santa Catarina no denominado Setor F, que tem um papel importante no contexto, por atender toda a Instituição.

O estudo pretende responder se os procedimentos adotados no processo de microfilmagem de documentos e sua aplicabilidade no Setor da Universidade Federal de Santa Catarina estão em conformidade com a legislação vigente, sendo um facilitador para efetivação de melhorias na gestão. Pretende também enfatizar a existência da legislação vigente e sua aplicação na microfilmagem de documentos da UFSC, bem como constatar os erros e acertos em sua utilização.

O método utilizado para o desenvolvimento da pesquisa é o indutivo, que foca a realidade e busca elucidar as ligações ocasionais em situações cotidianas complexas para tratamento, por meio de experimentos ou levantamento de dados, com o suporte da pesquisa bibliográfica e documental (YIN, 2001).

Esta pesquisa se caracteriza por uma abordagem qualitativa e de acordo com os objetivos propostos pode ser classificada como descritiva, buscando melhorar as práticas por meio da observação.

Quanto à abordagem, esta pesquisa é predominantemente qualitativa, que consiste em descrever a complexidade da realidade de determinado problema, analisa a interação entre certas variáveis, compreende e classifica determinados processos dinâmicos vividos por grupos sociais. Na perspectiva de Triviños (1987), a pesquisa qualitativa possui um caráter descritivo, que permitem corroborar os resultados e estabelecer alguns pontos de vista, utilizando-se frequentemente de transcrição de entrevistas e depoimentos.

Além disso, esse tipo de pesquisa contribui no processo de mudança de determinado grupo, e possibilita, em um nível de profundidade maior, a compreensão das particularidades. Conforme Richardson (1999, p.80), “os estudos que empregam esta metodologia (qualitativa) podem analisar a interação de certas categorias, relatar a complexidade de determinado problema, compreender e classificar processos dinâmicos vividos por grupos sociais".

Minayo (2007, p.21) destaca que a abordagem qualitativa de um problema se justifica por ser uma forma adequada para entender a "natureza de um fenômeno social pois o método qualitativo é o que se aplica ao estudo da história, das relações, das representações, das crenças, das percepções e das opiniões", que é produto das "interpretações que os humanos fazem a respeito de como vivem, constroem seus artefatos e a si mesmo, sentem e pensam". 
No que diz respeito ao enfoque, também conhecido como enquadramento quanto aos objetivos, esta pesquisa é caracterizada como sendo de ordem descritiva, pois tem a intenção de mapear uma realidade científica e descrever as características da mesma. A pesquisa descritiva possui como propósito descrever as peculiaridades, sobremaneira, as características de determinada população ou fenômeno. Sobretudo, adota técnicas padronizadas de coleta de dados. A pesquisa descritiva consiste em descrever, relatar, identificar, comparar dentre outros aspectos (BEUREN et al, 2010).

Para a coleta de dados, foi utilizada a técnica da entrevista semiestruturada que possibilitou um contato direto do pesquisador e sujeito entrevistado. Como instrumento norteador, foi utilizado um roteiro que orientou as perguntas.

Richardson (1999) vê na entrevista um procedimento que permite aumentar a empatia entre as pessoas e possibilita a transmissão de informações de um indivíduo para o outro, onde as dúvidas relativas ao objeto de estudos são esclarecidas pelo entrevistador ao entrevistado. As percepções do entrevistador observadas durante a entrevista também são consideradas fruto da mesma. Foram realizadas entrevistas com o Gestor (G) do setor de microfilmagem e com os cinco Colaboradores $(\mathrm{C} 1, \mathrm{C} 2, \mathrm{C} 3, \mathrm{C} 4, \mathrm{C} 5)$ que atuam diretamente nas atividades de microfilmagens.

Em complemento ou paralelo às entrevistas foi utilizada a técnica da observação direta que, Richardson (2008) destaca como uma possibilidade de melhor perceber um fenômeno no seu todo ou em algumas de suas partes. Esta foi desenvolvida em concomitância com as entrevistas, mais especificamente nos locais onde são desenvolvidas as atividades de microfilmagens. Como complemento destas duas técnicas de coleta de dados foi desenvolvida a pesquisa documental, através do acesso a registros e documentos do setor de microfilmagens.

Para a análise dos dados, conforme orienta Freitas et al. (1997), foi desenvolvida a análise de conteúdo, que pode ser definida como um conjunto de instrumentos metodológicos, que possibilita analisar diferentes fontes de conteúdo, verbais e não-verbais.

Quanto à interpretação, a análise de conteúdo transita entre dois polos: o rigor da objetividade e a fecundidade da subjetividade. É uma técnica refinada, que exige do pesquisador, disciplina, dedicação, paciência e tempo. Faz-se necessário também, certo grau de intuição, imaginação e criatividade, sobretudo na definição das categorias de análise. Jamais esquecendo do rigor e da ética, que são fatores essenciais (FREITAS, et al., 1997). 
Quanto às análises dos conteúdos, optou-se por seguir as orientações de Bardin (2009, p.44), que propõe um conjunto de técnicas de análise das comunicações visando obter por procedimentos sistemáticos e objetivos de descrição do conteúdo das mensagens, indicadores que permitam a inferência de conhecimentos relativos às condições de produção/recepção destas mensagens.

\section{ANÁLISE E DISCUSSÃO DOS RESULTADOS}

Fundada no ano de 1960, a massa documental da Universidade Federal de Santa Catarina foi tornando-se cada vez mais volumosa e, com isso, como foi verificado na pesquisa, ocorreu uma perda significativa de documentos no período anterior a criação do Serviço de Microfilmagem da UFSC, pois não havia transferência dos documentos dos Arquivos Setoriais para o Arquivo Central e, tampouco, existia arquivos adequados para a guarda dos documentos.

Na década de 1970 as unidades administrativas e de ensino da UFSC guardavam em seus arquivos setoriais um amontoado de documentos, que segundo o Gestor, causavam congestionamentos dos mesmos; difícil acesso às informações; constatação de um grande volume documental; inexistência de métodos padronizados; eliminação indiscriminada; dispersão e má conservação dos documentos, fazendo com que a história e a memória da UFSC fossem perdidas.

Em 1988 foi criada a Divisão de Arquivo Central do Departamento de Serviços Gerais (DSG), designando um servidor, através da Portaria n ${ }^{0}$ 1088/GR/1988, para exercer a função de diretor. No início deste mesmo ano foi denominado um grupo de trabalho, através da Portaria $\mathrm{n}^{\mathrm{o}}$ 111/GR/1988, para elaborar a primeira Tabela de Temporalidade dos Documentos da Instituição.

Em 1997, quase uma década após sua criação, a Divisão de Arquivo Central enfrentou uma nova situação desafiadora: a junção da Divisão de Arquivo Central com a Divisão de Microfilmagem, mudando definitivamente a estrutura do arquivo. Nova mudança ocorre na denominação desta Divisão em 2001, que passa a ser chamada de Divisão de Processamento Técnico do Acervo Documental (DPTAC). A partir desta mudança, ficou comprovada a necessidade da reestruturação do Arquivo Central da UFSC, sendo encaminhado ao Diretor do Departamento de Material e Serviços Gerais, Memorando 010/2001, com Parecer Técnico que deu origem ao Processo $n^{\circ} 100455 / 2002$, indicando discordância frente a nova 
nomenclatura da Divisão do arquivo central, sendo solicitado que o arquivo central tivesse sua própria divisão.

Em 2005 foi encaminhado o Ofício $\mathrm{n}^{\mathrm{o}}$ 01/AC/2005, contendo a proposta de reestruturação do Arquivo Central: transformar o serviço de Preparação, Restauração, Produção e Arquivo em Divisão do Arquivo Central. Esta solicitação foi consolidada, através da Portaria n ${ }^{0}$ 504/GR/2005, criando assim a referida Divisão, designando servidor, através da Portaria $n^{0} 512 / \mathrm{GR} / 2005$, para exercer a função de diretor da mesma.

Atualmente o Serviço de Microfilmagem da UFSC está vinculado a Divisão do Arquivo Central, pertencente a Pró-Reitoria de Infraestrutura (PROINFRA), com o objetivo de preservar a documentação da Universidade.

Relatos dos entrevistados ilustram como era antes da organização e estruturação da microfilmagem do Arquivo Central: "os documentos eram armazenados em qualquer lugar, como corredores" (Colaborador 1). "Ocorreram perdas com alguns documentos em razão de pequenas inundações ou devido à desordem no armazenamento dos documentos, sem nenhum tratamento arquivístico" (Colaborador 3). Com relação a um sistema de arquivos destacaram que "ainda não havia um Sistema de Arquivo para coordenar e desenvolver a política e a gestão arquivística de documentos da Universidade, apesar de existir alguns procedimentos e instrumentos, como a TTD, termo de transferência, termo de eliminação” (Gestor).

Os Colaboradores entrevistados destacaram também que "anteriormente à inauguração do Setor de Microfilmagem, todos os documentos em suporte papel da universidade, ficavam nos seus departamentos, onde havia muita desorganização e um acúmulo gradual de documentos" (C3, C4). Pode se afirmar que este fato ocorreu somente antes de iniciar o processo de microfilmagem na UFSC, até o ano de 1981.

Todo o processo de microfilmagem passou a ser realizado pelo setor, desde o critério de escolha dos documentos até a entrega dos microfilmes aos departamentos. Para Feijó (1988, p.147), “o arquivo escolar microfilmado consiste na transformação de toda a massa documental, do estado original para a forma de microfilme". Mas isso parece não acontecer na UFSC, pois os dados mostram que "a documentação microfilmada era bastante diversificada, mas a maioria, após determinação do grupo de trabalho, ficou concentrada na parte acadêmica e funcional" (C2).

Os registros documentais mostram que havia no Departamento de Administração Escolar (DAE) dois corredores de documentos com um grande risco de o piso ceder, devido 
ao peso excessivo. Por esse motivo, foi o primeiro departamento escolhido para a realização da microfilmagem dos documentos. Na ocasião, essa documentação foi levada para o Setor de Microfilmagem, dando início ao processo na instituição.

Como critério estabelecido pelo Setor de Microfilmagem, o primeiro passo para iniciar o processo de microfilmagem foi a escolha do departamento ou setor com o maior volume documental de valor secundário (histórico), sendo definida deste modo a seguinte ordem para a microfilmagem dos documentos: a) Departamentos Administrativos; b) Departamentos Acadêmicos; c) Órgãos Suplementares; d) Departamento de Pesquisa e Extensão.

Conforme depoimento do Gestor:

[...] no começo, todos os documentos eram microfilmados, sem nenhuma avaliação. Após várias reuniões, da equipe responsável pelo serviço, decidiram que alguns documentos não seriam mais microfilmados, como por exemplo, documentação pessoal de aluno, pois a universidade não tinha interesse nessa documentação, em razão de não possuir valor secundário (histórico) para a instituição.

A primeira Comissão de Avaliação (CA) da UFSC foi nomeada em 1988, com a participação de dois bibliotecários, um administrador e um historiador. Porém, somente os bibliotecários e o historiador participavam efetivamente das reuniões e discutiam os prazos e os valores dos documentos. Isso nos remete às orientações de Couture et al. (1999), que afirma que a avaliação documental é o ato de julgar os valores dos documentos arquivísticos (valor primário e valor secundário) e de decidir sobre os períodos de tempo em que os valores se aplicam a esses documentos, dentro de um contexto de relação entre o organismo produtor e os documentos arquivísticos gerados no desenvolvimento de suas atividades.

Faria (2006) observa que o esforço de depuração e racionalização do conjunto de documentos (arquivo) de uma instituição ou pessoa física, por meio da função arquivística de avaliação, gera na maioria dos casos um instrumento de gestão arquivística denominado Tabela de Temporalidade Documental (TTD). Portanto, a tabela de temporalidade é o instrumento desenvolvido por arquivistas para auxiliar na transferência, no descarte e na migração do suporte dos documentos da instituição, com vistas à racionalização do espaço físico e para facilitar a gestão dos documentos essenciais ao funcionamento da organização e à pesquisa informacional; ela traduz o conhecimento dos gestores sobre os prazos de guardas dos documentos arquivísticos da instituição.

Atualmente a UFSC está constituindo legalmente sua Comissão Permanente de Avaliação de Documentos (CPAD). A CPAD tem por finalidade assessorar a Divisão de 
Arquivo Central nas ações e procedimentos referentes à avaliação documental, também orientar e realizar análise, avaliação e seleção da produção documental acumulada. Além disso, deve ser formada por representantes dos mais importantes setores da instituição.

Os procedimentos adotados, constantes nos registros documentais, para o processo de microfilmagem na UFSC, visando tratamento arquivístico a documentação a ser microfilmada, é descrita no quadro 1:

Quadro 1 Tratamento arquivístico e de microfilmagem

\begin{tabular}{|c|c|}
\hline $\begin{array}{l}\text { Etapa anterior ao } \\
\text { processo de } \\
\text { microfilmagem: }\end{array}$ & $\begin{array}{l}\text { - Documentação não estava organizada. } \\
\text { - Documentação com clipes, amassada e molhada. }\end{array}$ \\
\hline $\begin{array}{l}\text { Etapa de preparação da } \\
\text { documentação: }\end{array}$ & $\begin{array}{l}\text { - Ocorria a higienização dos documentos, onde eram retirados objetos } \\
\text { metálicos, como clipes e grampos; } \\
\text { - Pequenos reparos (eram realizados em documentos muito danificados } \\
\text { ou rasgados); } \\
\text { - Eram desamassados. }\end{array}$ \\
\hline $\begin{array}{l}\text { Etapa posterior a } \\
\text { microfilmagem: }\end{array}$ & $\begin{array}{l}\text { - Transferência: quando era necessário guardar documentos por mais } \\
\text { tempo, conforme prazos estabelecidos, os documentos eram devolvidos } \\
\text { para seus departamentos de origem, conforme determinava a TTD; } \\
\text { - Descarte: os documentos eram eliminados quando os prazos } \\
\text { estipulados haviam esgotado, segundo a TTD; } \\
\text { - Recolhimento: não era realizado, por falta de espaço no arquivo } \\
\text { Central. }\end{array}$ \\
\hline $\begin{array}{l}\text { - Etapa inicial do } \\
\text { processo de } \\
\text { microfilmagem }\end{array}$ & $\begin{array}{l}\text { - Nome da organização e data do início da microfilmagem; número do } \\
\text { filme em ordem crescente, codificado, quando necessário; } \\
\text { - Termo de abertura do filme (deve conter nomes e assinatura do } \\
\text { responsável direto pela documentação arquivada e do responsável pelo } \\
\text { setor de microfilmagem); }\end{array}$ \\
\hline $\begin{array}{l}\text { - Etapa final do } \\
\text { processo de } \\
\text { microfilmagem }\end{array}$ & $\begin{array}{l}\text { - Rolo: o nome da organização e data do término da microfilmagem; } \\
\text { - Ordem de colocação dos documentos contidos no filme; } \\
\text { - Indicativo de final de filme; } \\
\text { - Termo de encerramento do filme. }\end{array}$ \\
\hline
\end{tabular}

Fonte: Documentos da pesquisa (2015).

As etapas de conferência da massa documental, bem como, a organização e avaliação, não eram realizadas. De acordo com a legislação, recomenda-se que todas as etapas da gestão documental devem ser realizadas antes do processo, sendo a microfilmagem uma etapa de preservação da documentação. Sem uma eficiente gestão, os documentos podem se perder.

Quanto as exigências da necessidade de que haja no final do rolo o termo de encerramento do filme, "o Setor de Microfilmagem da UFSC adota procedimentos em conformidade com a legislação vigente, Decreto $N^{0}$ 64.398/69, que determina a necessidade de haver no final do rolo o nome da organização e data do término da microfilmagem" (C5), 
que é ordem de colocação dos documentos contidos no filme, indicativo de final de filme e termo de encerramento do filme.

Quanto ao processamento dos filmes, são utilizados equipamentos e técnicas que assegurem ao filme, alto poder de definição, densidade e durabilidade. O método de microfilmagem utilizado pela UFSC, até o ano de 2005, segundo a pesquisa, "era o simplex, sendo que a microfilmadora planetária (KODAK) era o equipamento utilizado no processo, que é uma máquina de campo fixo. Essa máquina é indicada para os livros, plantas e folhas soltas microfichas, muito realizado no setor" (C4).

Existe no local uma máquina leitora/copiadora (KODAK) Starvue, modelo 14680, que serve para ler o filme e reproduzir o documento em seu suporte de origem, o papel. A cópia em papel pode ser reproduzida pelo sistema fotográfico tradicional, por aparelho leitorcopiador, processo eletrostático ou outros que se assegurem reprodução fiel e durabilidade, conforme determina a Lei $N^{0} 5.433 / 1968$ e Decreto $N^{\circ}$ 64.398/1969.

A reveladora Drhero, Modelo Micromatic JKR de filmes, também é encontrada no setor, mas a sala de revelação foi totalmente desativada em 2001, em razão de um estudo realizado na instituição e, "foi verificado na ocasião que o custo-benefício era maior se fosse terceirizado o processo de revelação" (C2). Pode-se constatar que o maquinário que ainda não existe no setor é a duplicadora de filmes, "necessária quando o filme cópia estraga, por algum motivo" - como observa Souza Neto (1979, p. 37).

Conforme descreve o Gestor:

Após a microfilmagem o filme era passado pelo controle de qualidade, no próprio Setor. Se houvesse algum erro, esses documentos eram sinalizados e microfilmados novamente. Se ocorresse alguma irregularidade no filme, ele deveria ser incinerado ou fragmentado e todo processo era realizado novamente. Esse processo estava de acordo com as normas arquivíticas.

Existem dois tipos de microfilmes: o de prata, que tem valor do documento original; e o microfilme de diazo, que tem valor de cópia. A única diferença entre os dois filmes é o valor dos documentos, pois a nitidez do filme e a impressão dos documentos são iguais. No caso da UFSC, os dois microfilmes produzidos são de prata.

Para o armazenamento, um dos microfilmes era guardado no Setor de Microfilmagem e o outro era enviado ao setor de origem. Como a maioria dos departamentos não tinham a leitora/copiadora, a chefia do Setor decidiu que as duas cópias ficariam na própria microfilmagem, mas "isso não deveria ocorrer, pois no caso de um incêndio ou uma inundação, todas aquelas informações podem se perder" (C4). Andrade (2006) salienta a 
necessidade do armazenamento em lugares distintos para a segurança da informação nos microfilmes.

$\mathrm{Na}$ UFSC, os documentos microfilmados são preservados em conformidade com as normas arquivísticas, quer dizer, os filmes são conservados com a temperatura e umidade recomendada, conforme defendido por Andrade (2006). Além disso, os documentos estão armazenados em armários adequados, ou seja, de aço e contra o fogo, conforme sugere o Conselho Nacional de Arquivos - CONARQ.

Segundo o Art. 25 da Lei 8.159/1991 é de responsabilidade penal, civil e administrativa destruir documentos de valor permanente ou considerado como de interesse público e social. Sendo assim, todos os documentos originais microfilmados, que não eram permanentes e tinham seus prazos de guarda esgotados, eram picotados e vendidos na UFSC. É muito importante que os documentos públicos eliminados sejam inutilizados, fragmentados ou incinerados, antes de seu descarte.

Para que esses documentos sejam eliminados corretamente é "necessário que se preencha um Termo de Eliminação de documentos microfilmados e registrados no Ministério da Justiça, o que não ocorria" (C3). Porém, conforme o novo Decreto Regulamentador do Microfilme, a eliminação de documentos, após a microfilmagem, dar-se-á por meios que garantam sua inutilização, sendo a mesma precedida de lavratura de termo próprio e após, a revisão e a extração do filme cópia.

Esses procedimentos nem sempre foram cumpridos, "as buscas pelos microfilmes eram realizadas em fichas, suporte papel, que hoje foram passadas para o meio digital, facilitando a busca e, consequentemente, o acesso" (C5). Hoje, a UFSC conta com cerca de 10 milhões de documentos microfilmados e sua consulta se dá numa média de 10 consultas diárias. Mas, para a validação, de acordo com Feijó (1988, p. 95), “convém lembrar que o sistema de microfilmagem aplicado ao desenvolvimento de arquivos, além de registros especiais em livros apropriados, inclui a exigência legal de autenticação do microfilme em órgão designado para tal fim". Foi verificado que na UFSC existe a preocupação com a exigência legal da autenticação, conforme sugere o autor, sendo que todas as cópias que saem do setor levam o carimbo de autenticidade do documento.

Em 2005 a Divisão de Arquivo Central, na qual o Setor de Microfilmagem está subordinado, elaborou um projeto visando o Gerenciamento Eletrônico de Documentos (GED). A ideia era desativar a microfilmagem convencional e implantar o Sistema Híbrido, 
onde o microfilme é produzido a partir da imagem digital de documentos denominado, microfilme eletrônico.

Em 2006 foi realizado o último processo de microfilmagem e em 2007 foi implantado oficialmente na universidade o GED. Hoje a instituição possui o chamado Sistema Híbrido, onde uma única máquina é capaz de microfilmar e digitalizar. Isso ocorreu porque o custo do microfilme estava muito elevado e não dava uma autonomia aos departamentos, pois os mesmos não tinham leitoras/copiadoras nos seus setores, tendo que se deslocar até o setor de microfilmagem que tinha a custódia dos microfilmes dificultando, assim, a busca da informação. "Resolvia o problema do volume documental e acabava criando outro, de acesso a informação" (C4).

Atualmente com a digitalização, o setor passou a se chamar Serviço de Microfilmagem e Digitalização. Todos os departamentos que tiveram seu acervo digitalizado têm acesso às informações, diretamente do seu computador, em sua mesa de trabalho. $\mathrm{O}$ software utilizado como ferramenta é o Neutron, de propriedade da empresa MGS, de Porto Alegre/RS.

O Neutron permite que o usuário realize consultas em diferentes bases de dados para entregar informações diretamente no seu aplicativo, trazendo agilidade e precisão na busca de informações. Para determinar a massa documental que será microfilmada é necessário realizar um estudo da consulta e do valor desses documentos. Hoje, a massa documental que está sendo digitalizada são os dossiês dos servidores, onde a consulta por essa informação é diária e a guarda é de 100 anos.

Não há um Sistema de Arquivo para coordenar e desenvolver a política e a gestão arquivística de documentos da Universidade. O que seria importante para agilizar o acesso às informações produzidas em cumprimento de suas atribuições, contribuindo para a eficiência administrativa e acadêmica e a preservação da memória institucional - servindo como referência, prova ou fonte de pesquisa necessária a implantação e consolidação do sistema. Sem esse Sistema de Arquivo não é possível promover uma eficiente gestão, preservação e o acesso às informações na sua esfera de competência, causando uma deficiência nos processos de automação utilizados.

Com a revisão da literatura e a articulação dos dados coletados com a legislação vigente foi constatado que o setor de microfilmagem procede de acordo com as determinações do CONARQ, com relação ao maquinário utilizado e a operacionalização do processo de 
microfilmagem. Pode-se também, identificar os departamentos favorecidos pelo processo e, consequentemente, a documentação da UFSC que foi microfilmada, com a intenção de preservar a informação gerada pela universidade. No entanto, pode-se constatar que pela inexistência de profissionais arquivistas na instituição até o período, não houve uma "preocupação" - ou, quem sabe, muito mais pelo desconhecimento técnico - com a elaboração do Termo de Eliminação, essencial para o descarte dos documentos.

Com a recente substituição do método de microfilmagem pelo Sistema Híbrido, foi facilitado o acesso aos documentos agilizando as rotinas administrativas que, para a UFSC, na atualidade, parece ser a melhor opção. Até porque, a microfilmagem já não atendia plenamente as demandas da Instituição.

\section{CONSIDERAÇÕES FINAIS}

A partir dos resultados e análise apresentados, e de acordo com os objetivos propostos na pesquisa, é possível apresentar algumas considerações e recomendações.

O objetivo da microfilmagem na UFSC é a redução da necessidade de espaço físico. Isto permite, a um só tempo, evitar o acúmulo de documentos e garantir o acesso rápido da informação. Destaca-se, além disso, que foi observado que não há perda de informação com o emprego de um sistema de microfilmagem, pois o que ocorre é, sobretudo, a mudança do suporte, de papel para o filme.

Com relação aos procedimentos práticos e as rotinas, ficou evidenciado que se fundamentam conforme critérios e normas teóricas que regem a microfilmagem. No que se refere aos equipamentos utilizados, também foi verificado que são adequados, segundo os procedimentos técnicos. Há microfilmadora planetária, rotativa, leitora/copiadora e processadora de filmes.

Quanto aos benefícios que a microfilmagem trouxe para a UFSC foi possível verificar que o tratamento da documentação, mesmo que parcial, permite a diminuição da massa documental acumulada, visando à preservação do documento permanente - de acordo com os respondentes, este é um dos aspectos positivos do processo de microfilmagem. Pôde-se perceber, ao longo da pesquisa, que é consenso que o intuito do processo é facilitar e agilizar o acesso/busca de documentos, e isto de coaduna aos interesses da comunidade universitária.

Com o crescimento da Universidade, com mais 4 novos campus, a microfilmagem passou a não mais satisfazer, de modo integral, as necessidades da instituição. Conforme constatado, a inexistência de "leitoras" foi um fator considerado decisivo para a busca de 
novas soluções. Assim, para atender as novas demandas, recentemente foram buscadas novas soluções como a implantação de um Sistema Híbrido.

O Sistema Híbrido surgiu como possibilidade de solução para agilizar o acesso aos documentos nos departamentos, via rede, a fim de preservar os documentos permanentes, com o microfilme eletrônico obtido através da digitalização/microfilmagem simultâneas.

A Microfilmagem eletrônica oferece a melhor forma para arquivamento de informações. A partir de arquivos digitais, organizados e classificados (por tipo de documento e data) cria-se cópias dos registros em mídia micrográfica. Além disso, gera um arquivo de índice contendo informações de cada imagem microfilmada e esse arquivo de índice pode ser importado para qualquer banco de dados, facilitando assim a sua pesquisa no microfilme.

O problema da falta de espaço não deixou de existir pois ainda não foi implantado um Sistema de Arquivos formalizado na instituição. Porém, com a contratação de nove arquivistas o processo de avaliação documental e descarte de documentos estão sendo executados em conformidade com a legislação arquivística brasileira, o que não deixa de ser um dado expressivo.

O novo sistema de GED, que vem sendo implantado na instituição desde 2005, é uma etapa importante e necessária na organização e gestão informacional da UFSC. Porém, somente com a implantação de um Sistema de Arquivos será possível o gerenciamento total de todos os arquivos em todos os seus suportes. Por fim, e em face de todo o exposto, vale asseverar que é imprescindível a implantação, com certa urgência, de um Sistema de Arquivo que promova a gestão, preservação e acesso aos documentos na sua esfera de competência e com significativo grau de excelência.

\section{REFERÊNCIAS}

ANDRADE, A. N. de. Microfilme: passado, presente e futuro da preservação documental. São Paulo: CEDIC, 2007.

ANDRADE, A. N. de. Os processos da Microfilmagem. São Paulo: CEDIC, 2006.

ANTUNES, M. T. F. A microfilmagem na perspectiva da preservação documental: um estudo realizado nas Universidades Públicas Brasileiras que congregam curso de Arquivologia. Santa Maria: 2009

BARDIN, L. Análise de Conteúdo. Tradução de Luís A. Reto e Augusto Pinheiro. 5.ed. Lisboa: Edições 70, 2009.

BECK, I. Manual de preservação de documentos. Rio de Janeiro: Arquivo Nacional, 1991.

BELLOTTO, H. L. Arquivos permanentes: tratamento documental. São Paulo:

T.A.Queiroz, 1991. 
BEUREN, Ilse M.; LONGARAY, André A.; RAUPP, Fabiano M.; SOUSA, Marco A. B.de; COLAUTO, Romualdo D.; PORTON, Rosimere Alves de B.. Como elaborar trabalhos monográficos em contabilidade: teoria e prática. 3. ed. São Paulo: Atlas, 2010.

BRASIL. Decreto n. 1.799, de 30 de janeiro de 1996. Regulamenta a Lei $n^{\circ} 5.433$, de 8 de maio de 1968, que regula a microfilmagem de documentos oficiais, e dá outras providências. Diário Oficial da União, de 31 de janeiro de 1996.

BRASIL. Lei 5.433, de 8 de maio de 1968. Regula a microfilmagem de documentos oficiais e dá outras providências. Diário Oficial da República Federativa do Brasil, de 10/05/1968.

BRASIL. Lei 8.159, de 8 de janeiro de 1991. Dispõe sobre a política nacional de arquivos públicos e privados e dá outras providências. Diário Oficial da República Federativa do Brasil, n. 6, janeiro de 1991.

BRASIL. Resolução ${ }^{\circ} 10$ de 6 de dezembro de 1999. Dispõe sobre a adoção de símbolos ISO nas sinaléticas a serem utilizadas no processo de microfilmagem de documentos arquivísticos. Diário Oficial da União, de 22 de dezembro de 1999.

COUTURE, Carol; ROUSSEAU, Jean-Yves. Os Fundamentos da Disciplina Arquivística. Lisboa: Dom Quixote, 1999.

CUNHA, Murilo Bastos da. Desafios na construção de uma biblioteca digital. Ciência da Informação, Brasília, v. 28, n. 3, p. 257-268, set./dez. 1999. Disponível em: $<$ http://www.ibict.br/cienciadainformacao/rst/viewarticle.php?id=323 $>$. Acesso em: 28 jul. 2004.

FARIA, Wadson Silva. A normalização dos instrumentos de gestão arquivística no Brasil: um estudo da influência das resoluções do CONARQ na organização dos arquivos da Justiça Eleitoral Brasileira. Dissertação (Mestrado em Ciência da Informação) - Departamento de Ciência da Informação e Documentação da Universidade de Brasília (UnB), Brasília, 2006.

FEIJÓ, V. de M. Documentação e arquivos. Porto Alegre: SAGRA, 1988. FOX, L.

Microfilmagem de preservação: um guia para bibliotecários e arquivistas. Tradução de. José Luiz Pedersoli Jr. 2. ed. Rio de Janeiro: Projeto Conservação Preventiva em Bibliotecas e Arquivos: Arquivo Nacional, 2001. 54 p. (PROJETO CPBA, 48). Disponível em: $<$ http://siarq02.siarq.unicamp.br/cpba/pdf_cadtec/48.pdf $>$. Acesso em: 10 março 2007.

FREITAS, H. et al. Informação e decisão: sistemas de apoio e seu impacto. Porto Alegre: Ortiz, 1997.

LUTHER, F. Microfilme: sua história (1839-1900). São Paulo: SOUZA NETO, 1979.

MINAYO, Maria Cecília de Souza. Pesquisa social. Petrópolis: Vozes, 2007.

PAES, M. L. Arquivo: teoria e prática. 3. ed. Rio de Janeiro: Editora FGV, 2004.

RICHARDSON, R. J. Pesquisa social. São Paulo: Atlas,1999.

SOUZA NETO, J.M. O microfilme. 2. ed. São Paulo: SOUZA NETO, 1979.

TRIVIÑOS, Augusto N. S. Introdução à pesquisa em ciências sociais: a pesquisa qualitativa em educação. São Paulo: Atlas, 1987.

YIN, R. K. Estudo de caso: planejamento e métodos. Porto Alegre: Bookman, 2001. 